\title{
Study of Prevalence of Allergy among College Students
}

\author{
Kamal Mehta \\ Assistant Professor, P.G Department of Zoology, J.C.D.A.V. College, Dasuya (Distt. Hoshiarpur) Punjab, India
}

\begin{abstract}
Objective: To assess the prevalence and pattern of Allergic diseases among College Students. Methods: 200 College Students from Dasuya town of district Hoshiarpur situated at $31.82^{\circ} \mathrm{N} 75.66^{\circ} \mathrm{E}$ of Punjab, India included in the present survey. A detailed Performa was filled by all the participants. Data was collected about the allergen, family history, duration and time of allergic reaction and medication. The allergy was further subcategorized on the basis of type of allergen into ten different types. In addition, information was collected about the age, sex, place of residing and medication taken for allergy. None of the participant was smoker or alcohol drinker. Results: Of all the Students included in the present study $63.5 \%$ were suffering from one or another type of allergy. Amongst the allergens, dust was the most common cause of allergy (24\%) followed by Sunlight (17\%) and Cosmetics (11\%). The other allergens include Food, Pollen grains, Climate, Drugs, synthetic clothes, Detergents and Metals (48\%). Out of the allergic participants $19 \%$ were having allergic reaction in the form of sneezing, $18 \%$ with a feeling of running nose and $16 \%$ had itching, $13 \%$ had rashes, $12 \%$ had watery eyes, $10 \%$ had burning sensation, $10 \%$ had Chest Congestion and $2 \%$ had nausea. In most of participants the allergic reaction remained for hours (29\%) while in some cases it remained for only minutes (22\%). In other participants it remained throughout the year (7\%) or for few months (17\%) while in still small number of participants it remained for days (25\%). Conclusion: This study suggests that allergy is a common problem among College students and the most common allergen is dust. Since till date there are no permanent cures for allergies and it can be managed only with proper prevention and treatment. One of the plausible reasons for increase in allergy is change in environment. This information will provide important insight for targeting allergy prevention and management programs and interventions.
\end{abstract}

Keywords: Allergy, Allergen, Allergic Reaction, Prevalence.

\section{Introduction}

All organisms come in contact with the foreign materials living as well as non living, namely viruses, rickettisia, bacteria, protozoan, fungi, worms, arthropods, dust, pollen grains etc. In order to maintain homoeostasis and survive, the organisms have evolved a variety of defense mechanisms against the disease causing viruses or foreign molecules. One such reaction of the body against foreign molecules is referred as Allergy. Allergy is characterized by an overreaction of the human immune system to a foreign substance/allergen that is eaten, breathed into the lungs, injected or touched. A person develops an allergic reaction when the immune system cannot tell the good from the bad and releases a type of chemical called histamine to attack the harmless substance as if it were a threat. Histamine produces many of the symptoms associated with allergies. These symptoms include Itching, watery eyes, persistent stuffy nose or ears, sneezing, runny nose, rashes, burning sensation and chest congestion. $50 \%$ of children and young people have one or more allergies within the first 18 years of life (Journal of Clinical \& experimental Allergy, 2009). Allergy is a chronic disease that is expected to affect more than $50 \%$ of all the Europeans in 10 years time (EAACI, 2011).Acc. to Allergy Statistics, millions of adults suffer from at least one allergy, with their numbers continuing to rise. Each year the numbers of allergy sufferers' increases by $5 \%$, half of all affected are being children. UK hospital admissions for food allergies have increased by $500 \%$ since 1990 (Gupta et al, 2011).Common allergens include food, climate, pet, metal, dust, sunlight, pollen grain, cosmetics and synthetic clothes. Although it is well known that pollens, dusts, fungi and insects are common offending allergens responsible for allergic reactions but relative frequency of allergy by these different groups of allergens may vary from place to place. Moreover, even in any one group (e.g. fungi or pollen or dust) the causal allergen may be different in different places depending on the type of local plantation, allergenicity of different pollens, dusts, insects, fungi, etc. present in the atmosphere and immunological state of the patients living in that environment.Most allergic reactions are not serious, but some, such as anaphylaxis, can result in an inability to breathe or a severe drop in blood pressure and can be fatal. Only a few allergies can be cured outright, but a variety of conventional and alternative treatments are available to relieve the symptoms.

Keeping in view the effects of allergies, the objectives of the present study is to assess the prevalence and pattern of Allergic diseases in the College Students involving following Parameters-

- Study the incidence of allergic subgroups based on type of allergen.

- To study the pattern of symptoms during the allergic reaction.

\section{Methodology}

200 College Students from the Dasuya town of district Hoshiarpur situated at $31.82^{\circ} \mathrm{N} 75.66^{\circ} \mathrm{E}$ of Punjab, India during the month of July 10,2015 to December 07,2015 included in the present survey. A detailed Performa was filled by the participants. Data was collected about the allergen,

\section{Volume 4 Issue 12, December 2015}




\section{International Journal of Science and Research (IJSR) \\ ISSN (Online): 2319-7064 \\ Index Copernicus Value (2013): 6.14 | Impact Factor (2014): 5.611}

family history, duration and time of allergic reaction and medication. Participants were then subdivided into ten subcategories based on the type of allergen. These include Sunlight, Dust, Climate, Detergents, Cosmetics, Metal, Food, Drugs, Synthetic Clothes and Pollen grains. Participants were further subdivided into two subcategories based on the information about the family history of allergic diseases and based on the age of onset of disease into childhood and late onset of allergic reaction. Any participants who had the first allergic reaction before the age of 12 years were included in childhood category and remaining in late onset category. In addition information was collected about the age, sex, place of residing, symptoms, duration and time of allergic reaction. None of the participant was smoker or alcohol drinker. Informed consent was taken from all the volunteers who participated in the present study.

\section{Results and Discussion}

Out of the 200 participants, 127 (63.5\%) were suffering from one or the other form of allergy and $73(36.5 \%)$ were found to be non-allergic as shown in [Table 1/Fig.1 (a,b)].

Table 1: Distribution of participants on the basis of allergy

\begin{tabular}{|r|c|c|c|}
\hline S.No & Subgroups & No of Individuals & \%age \\
\hline 1. & Allergic & 127 & 63.5 \\
\hline 2. & Non Allergic & 73 & 36.5 \\
\hline & Total & 200 & 100 \\
\hline
\end{tabular}

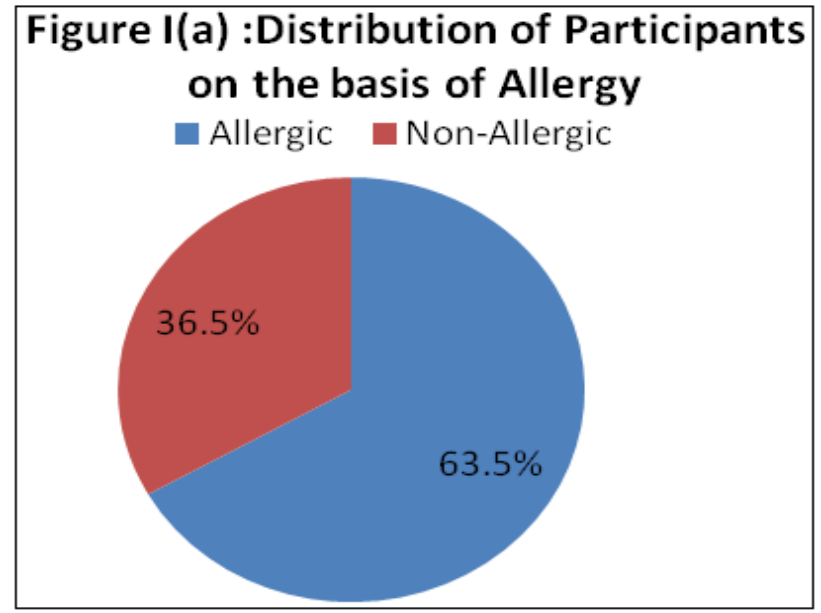

Figure I (b): Distribution of Allergy among participants

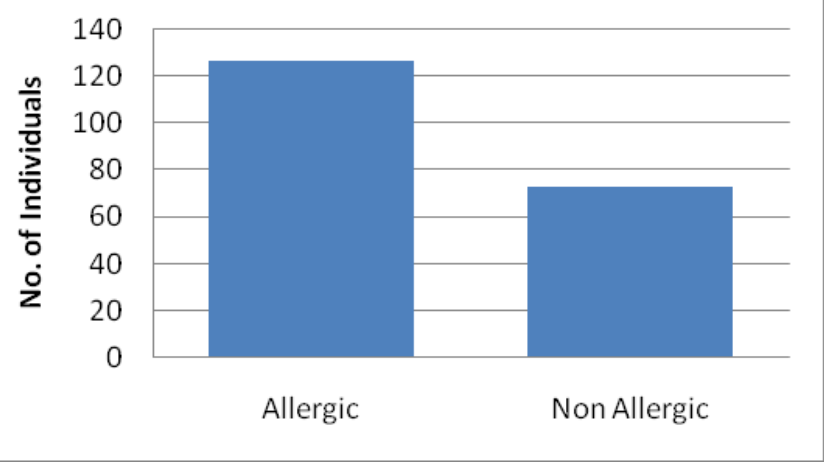

\subsection{Symptoms}

The 127 participants differ in the presentations of symptoms of allergy. The maximum number of participants has allergic reaction in the form of Sneezing $(19 \%)$ followed by running nose $(18 \%)$ and itching $(16 \%)$. The other symptoms include rashes, burning sensation, watery eyes, chest congestion and nausea [Table 2/Fig.2].

Table 2: Distribution of participants on the basis of Symptoms

\begin{tabular}{|r|c|c|c|}
\hline S.No & Allergy Symptoms & $\begin{array}{c}\text { No. of } \\
\text { Individuals }\end{array}$ & \%age \\
\hline 1. & Itching & 20 & 16 \\
\hline 2. & Rashes & 17 & 13 \\
\hline 3. & Burning Sensation & 13 & 10 \\
\hline 4. & Running Nose & 23 & 18 \\
\hline 5. & Watery Eyes & 15 & 12 \\
\hline 6. & Sneezing & 24 & 19 \\
\hline 7. & Chest Congestion & 12 & 10 \\
\hline 8. & Nausea & 03 & 02 \\
\hline
\end{tabular}

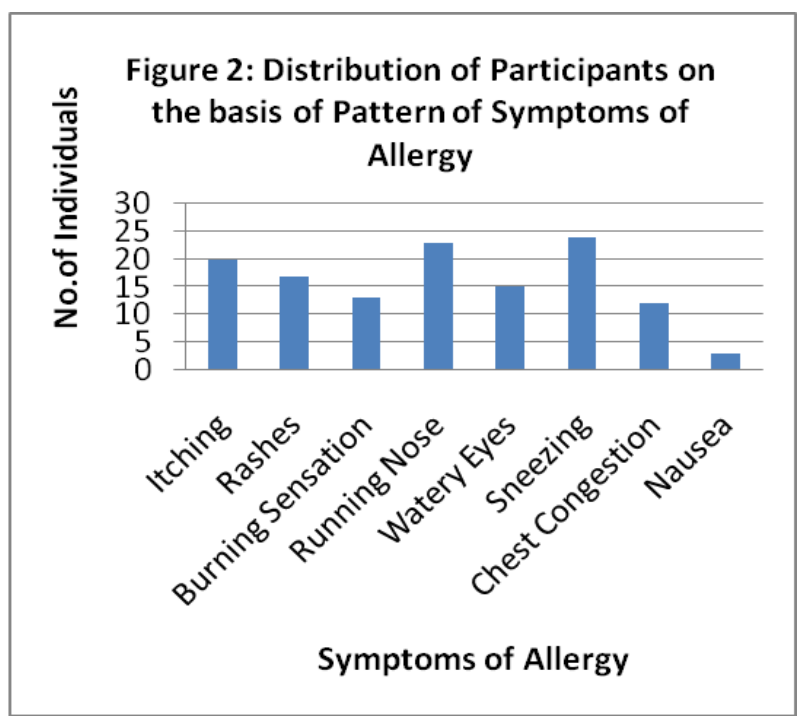




\section{International Journal of Science and Research (IJSR)}

ISSN (Online): 2319-7064

Index Copernicus Value (2013): 6.14 | Impact Factor (2014): 5.611

\subsection{Allergic subgroups based on the type of allergens}

When the allergic individuals were sub grouped on the basis of type of allergen ten different subcategories were formed [Table 3/Fig. 3].

Table 3: Distribution in allergic subgroups based on the type of allergen

\begin{tabular}{|c|c|c|c|}
\hline S.No. & Allergen & $\begin{array}{c}\text { No. of individuals Showing } \\
\text { Sensitivity to a Specific Allergen }\end{array}$ & $\begin{array}{c}\% \\
\text { age }\end{array}$ \\
\hline 1. & Sunlight & 21 & 17 \\
\hline 2. & Dust & 31 & 24 \\
\hline 3. & Climate & 07 & 06 \\
\hline 4. & Detergents & 06 & 05 \\
\hline 5. & Cosmetics & 14 & 11 \\
\hline 6. & Metal & 10 & 08 \\
\hline 7. & Food & 12 & 09 \\
\hline 8. & Drugs & 05 & 04 \\
\hline 9. & Synthetic Clothes & 13 & 10 \\
\hline 10. & Pollen grains & 08 & 06 \\
\hline
\end{tabular}

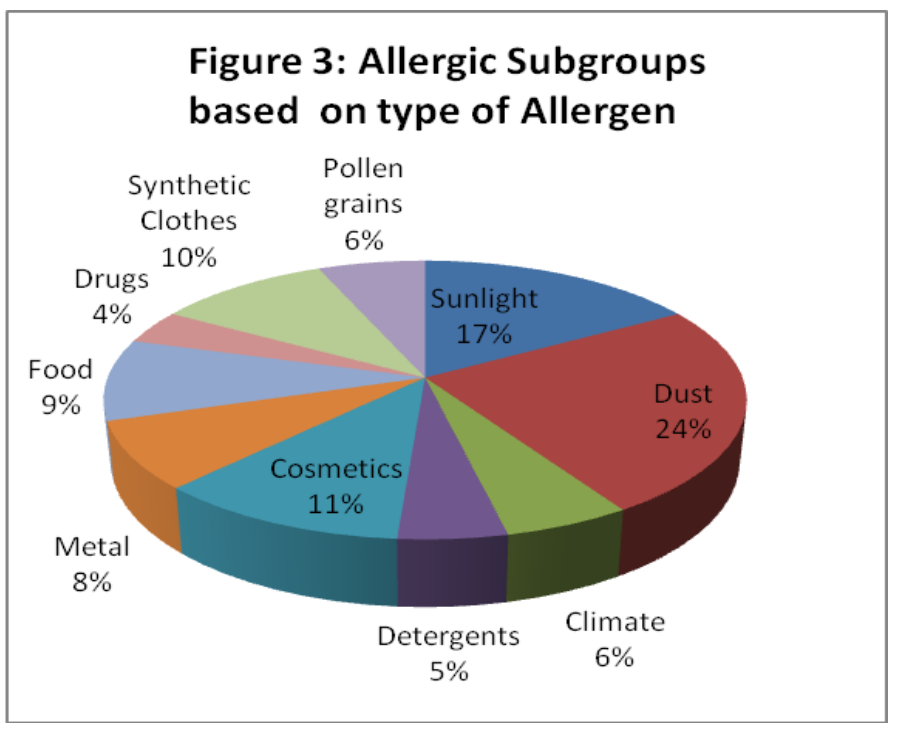

From the table 3 it is apparent that the maximum number of allergic individuals are suffering from allergy from dust (24\%) followed by the sunlight (17\%).

\subsection{Allergic subgroups based on the family history}

Earlier studies have reported the role of genes in the allergic responses. To validate the role of genes in allergy the data related to family history of allergy was collected On the basis of family history, individuals under study were divided into two subgroups: one with family history of allergy and other without any history [Table 4/Fig:4].

Table 4: Distribution of individuals in allergic subgroups based on the family history

\begin{tabular}{|c|c|c|c|}
\hline S.No & Family History (FH) & No of Individuals & \%age \\
\hline 1 & Positive FH & 77 & 61 \\
\hline 2 & Negative FH & 50 & 39 \\
\hline
\end{tabular}

\section{Figure 4: Distribution of Individuals in Allergic Subgroups based on the family history}

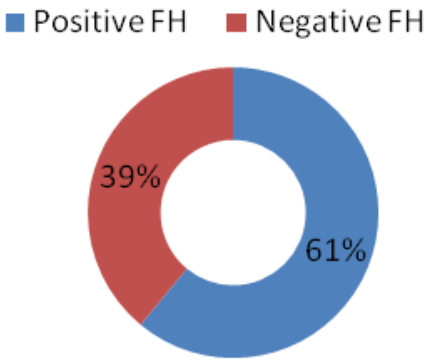

From the observational data, it was found that $61 \%$ participants showed positive family history for allergy, hence reflecting the role of genes and heredity in allergic reactions. Since the sample size is small and therefore, more samples need to be studied to validate the above results.

\subsection{Allergic subgroups based on the Age of onset}

Studies have reported difference in the distribution of allergies in different age groups. Food allergies have been reported mostly in children and generally these allergies to food are outgrown by children with time. In the present study, allergic have been divided into groups on the basis of age i.e. childhood allergic and late onset allergic. Childhoods allergic are those who develop allergic reaction before the age of 12 years. As evident from table 5/Fig. 5, 73\% of the individuals develop allergy after the age of 12 years. This could be because the participants who participated in the present study come across the allergen when they grew up.

Table 5: Distribution of individuals in allergic subgroups based on the age of Onset of disease

\begin{tabular}{|l|l|c|c|}
\hline S. No & Age of Onset & No of Individuals & $\%$ age \\
\hline 1. & Childhood & 34 & 27 \\
\hline 2. & Late Onset & 93 & 73 \\
\hline
\end{tabular}

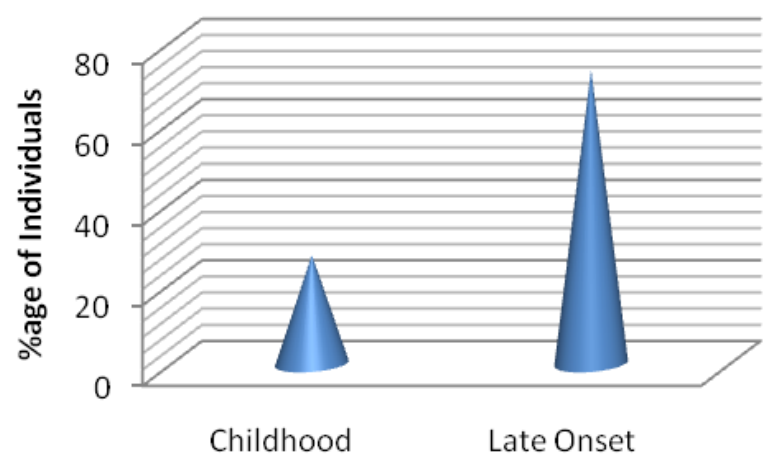

Figure 5: Age of Onset of Allergy 


\section{International Journal of Science and Research (IJSR) \\ ISSN (Online): 2319-7064 \\ Index Copernicus Value (2013): 6.14 | Impact Factor (2014): 5.611}

Information was also gathered about the duration of allergic reaction, time of attack, money spent on the medication. The study results as depicted in Table 6/Fig. 6, the maximum number of individuals had the allergic reaction for hours.

Table 6: Duration of Allergic Reaction in Participants

\begin{tabular}{|c|c|c|c|}
\hline S.No. & $\begin{array}{c}\text { Duration of } \\
\text { Allergic Reaction }\end{array}$ & No. of Individuals & \%age \\
\hline 1. & Throughout year & 09 & 07 \\
\hline 2. & Months & 21 & 17 \\
\hline 3. & Days & 32 & 25 \\
\hline 4. & Hours & 37 & 29 \\
\hline 5. & Minutes & 28 & 22 \\
\hline
\end{tabular}

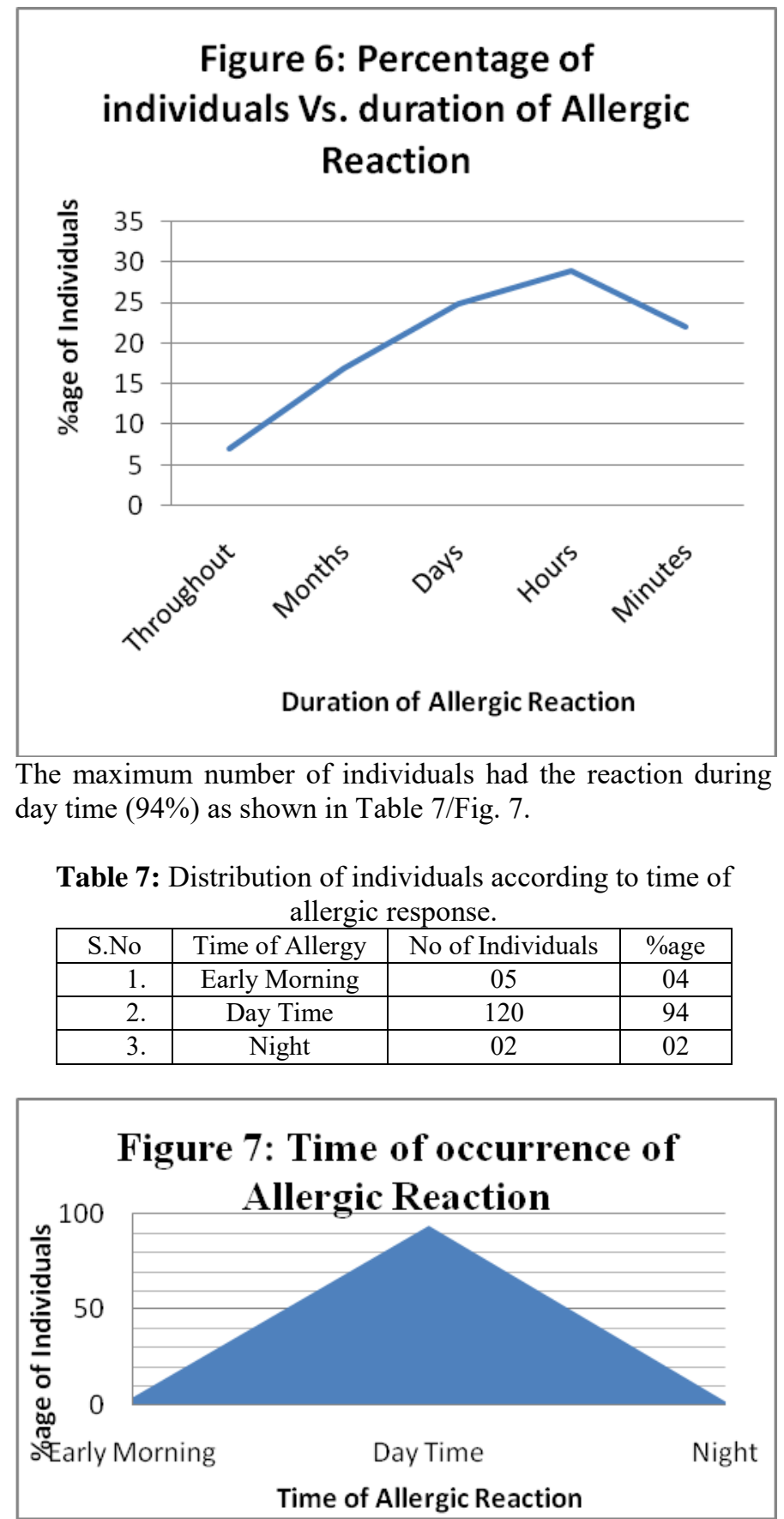

This study results showed that most of the people develop the allergic reaction during day time and the reaction stays for hours together.

\section{Conclusion}

This study shows that allergy is present in $63.5 \%$ of the population with dust as the most common allergen and the allergic reaction mainly comprises of sneezing, Running Nose and itching. This reaction occurs mostly during day time and remains for hours together.

\section{References}

[1] Aggarwal AN, Chaudhary k., Chhabra S. et al . Prevalence \& risk factors for bronchial asthma in Indian adults. A Multicentre study. Indian J. Chest Dis. Allied Sci. 2006,48:18-22.

[2] Bishop J, Hill D, Hosking C. 1990. Natural history of cow milk allergy: clinical outcome. J Pediatric 116:862-867.

[3] Bock S. 1987. Prospective appraisal of complaints of adverse reactions to foods in children during the first 3 years of life. Pediatrics 79:683-688.

[4] Bock SA, Atkins FM. 1989. The natural history of peanut allergy. J Allergy Clin Immunol 83:900-904.

[5] Das H, Rahim M.A. and Ramana Rao K.V. causative factors in bronchial asthma and skin testing with Local allergens Ind. J. Tub., Vol. XXVI, pg 82-86

[6] Eggesbo M, Botten G, Halvorsen R, Magnus P. 2001. The prevalence of allergy to egg: a population-based study in young children. Allergy 56:403-411.

[7] Gupta D., Aggarwal AN, Kumar R., Jindal SK. Prevalence of bronchial asthma \& association with environment tobacco smoke exposture in adfolescent school children in Chandigarh, North India. J.Asthma 2001, 38:501-507.

[8] Gupta, R, et al. The Prevalence, Severity and Distribution of Childhood Food Allergy in the United States. Pediatrics 2011; 10.1542/ped.2011-0204.

[9] Host A. 1994. Cow's milk protein allergy and intolerance in infancy. Some clinical, epidemiological,and immunological aspects. Pediatr Allergy Immunol 5:5-36.

[10] Jindal SK, Gupta D., Aggarwal AN et al. Study of prevalence of asthma in adults of North India using a standardized field questionnaire. J.Asthma 2000, 37: 345351.

[11] May C. 1976. Objective clinical and laboratory studies of immediate hypersensitivity reactions to food in asthmatic children. J Allergy Clin Immunol 58:500-515.

[12] Niestijl J, Kardinall A, Huijbers G, Vlieg-Boerstra B, Marten B, Ockhuizen T. 1994. Prevalence of food allergy and intolerance in the adult Dutch population. J Allergy Clin Immunol 93:446-456.

[13] Sampson H. 1988. Comparative study of commercial food antigen extracts for the diagnosis of food hypersensitivity. J Allergy Clin Immunol 82:718-726.

[14] Sampson H. 1996. Epidemiology of food allergy. Pediatr Allergy Immunol 7:42-50. 


\section{International Journal of Science and Research (IJSR) \\ ISSN (Online): 2319-7064}

Index Copernicus Value (2013): 6.14 | Impact Factor (2014): 5.611

[15] WHO White Book on Allergy 2011-2012 Executive Summary. By Prof. Ruby Pawankar, MD, PhD, Prof. Giorgio Walkter Canonica, MD, Prof. Stephen T. Holgate, BSc, MD, DSc, FMed Sci and Prof. Richard F. Lockey, MD. 